Open Access

\title{
The effects of selective head cooling versus whole-body cooling on some neural and inflammatory biomarkers: a randomized controlled pilot study
}

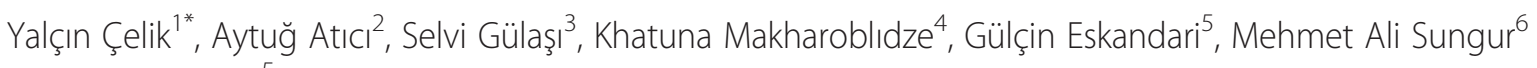
and Serin Akbayır ${ }^{5}$

\begin{abstract}
Background: Therapeutic hypothermia (TH) has become standard care in newborns with moderate to severe hypoxic ischemic encephalopathy (HIE), and the 2 most commonly used methods are selective head cooling (SHC) and whole body cooling (WBC). This study aimed to determine if the effects of the 2 methods on some neural and inflammatory biomarkers differ.

Materials and methods: This prospective randomized pilot study included newborns delivered after $>36$ weeks of gestation. SHC or WBC was administered randomly to newborns with moderate to severe HIE that were prescribed $\mathrm{TH}$. The serum interleukin (IL)-1 $\beta$, IL-6, neuron-specific enolase (NSE), brain-specific creatine kinase (CK-BB), tumor necrosis factor-alpha (TNF-a), and protein S100 levels, the urine S100B level, and the urine lactate/creatinine (L/C) ratio were evaluated 6 and $72 \mathrm{~h}$ after birth. The Bayley Scales of Infant and Toddler Development-III was administered at month 12 for assessment of neurodevelopmental findings.

Results: The SHC group included 14 newborns, the WBC group included 10, the mild HIE group included 7, and the control group included 9. All the biomarker levels in the SHC and WBC groups at 6 and $72 \mathrm{~h}$ were similar, and all the changes in the biomarker levels between 6 and $72 \mathrm{~h}$ were similar in both groups. The serum IL- 6 and protein S100 levels at $6 \mathrm{~h}$ in the SHC and WBC groups were significantly higher than in the control group. The urine $L / C$ ratio at $6 \mathrm{~h}$ in the SHC and WBC groups was significantly higher than in the mild HIE and control groups. The IL-6 level and $L / C$ ratio at 6 and $72 \mathrm{~h}$ in the patients that had died or had disability at month 12 were significantly higher than in the patients without disability at month 12 .

Conclusion: The effects of SHC and WBC on the biomarkers evaluated did not differ. The urine L/C ratio might be useful for differentiating newborns with moderate and severe HIE from those with mild HIE. Furthermore, the serum IL-6 level and the L/C ratio might be useful for predicting disability and mortality in newborns with HIE.
\end{abstract}

Keywords: Biomarkers, Hypoxic ischemic encephalopathy, Selective head cooling, Whole body cooling

\footnotetext{
*Correspondence: drycelik@yahoo.com

'Mersin University School of Medicine, Department of Neonatology Care Unit, 33343 Mersin, Turkey

Full list of author information is available at the end of the article
} 


\section{Background}

Worldwide, hypoxic ischemic encephalopathy (HIE) is a primary cause of disability and mortality in newborns [1-7]. Currently, therapeutic hypothermia (TH) is routinely used to treat moderate and severe HIE [8-13]. TH is administered as selective head cooling ( $\mathrm{SHC}$ ) or wholebody cooling (WBC), but it is not known if the efficacy of these 2 methods differ [14-19]. Regardless of which method is used, it is recommended that TH be initiated for HIE as early as possible, preferably within $6 \mathrm{~h}$ of birth [9]. The diagnosis of HIE and making the decision to start $\mathrm{TH}$ can be difficult. Furthermore, TH is not effective in all cases of HIE and despite administration of TH severe disability can occur $[1,20]$. As such, researchers have been trying to identify a biomarker that can be used to diagnose HIE, to determine if $\mathrm{TH}$ should be administered, and to predict prognosis [21-23].

Earlier studies have reported some promising biomarkers [21]. A recent study reported that TH administered using WBC suppressed cytokine levels in newborns with HIE, which was suggested to play a role in the neuroprotective effect of $\mathrm{TH}$ [8]. This finding suggests that SHC and WBC may have different effects on inflammatory and neuronal biomarkers. To the best of our knowledge, no study has compared the effect of SHC and WBC on biomarkers; therefore, the present study aimed to determine if the effects of these 2 methods on some neural and inflammatory biomarkers differ. An additional aim was to determine if the studied biomarkers are useful for predicting disability and mortality in newborns with HIE.

\section{Methods}

This prospective randomized study included newborns born after $>36$ weeks of gestation that were inpatients at Mersin University, School of Medicine, Neonatal Intensive Care Unit, Mersin, Turkey, between April 2010 and December 2011. The study protocol was approved by the Mersin University Ethics Committee and written informed consent was obtain from the families of the newborns. During randomization, age $>6 \mathrm{~h}$, severe intrauterine growth retardation, and congenial anomaly were considered exclusion criteria. HIE was diagnosed according to American College of Obstetricians and Gynecologists criteria [24], and modified Sarnat staging was used to classify HIE [25]. Passive cooling (turning off the incubator heater during transfer) was administered to newborns with HIE that were transferred from other hospitals.

The decision to administer $\mathrm{TH}$ to the newborns with HIE was based on having $\geq 1$ of criteria A, B, and C, as shown in Table 1. SHC or WBC was selected randomly via the closed envelope method. SHC was administered using a manually controlled device (Olympic Medical Cool Care System, Olympic Medical, Seattle, WA, USA), whereas WBC was administered using a room air conditioning
Table 1 Criteria indicative for therapeutic hypothermia

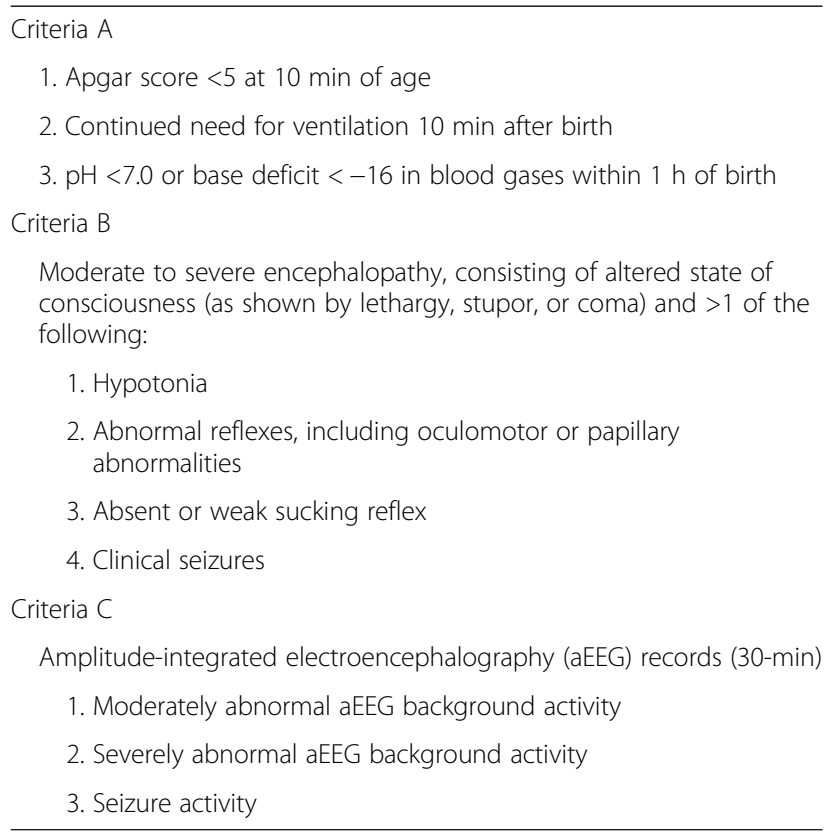

system. Body temperature was continuously monitored via rectal probes in the SHC and WBC groups. In both groups rectal temperature was recorded every $30 \mathrm{~min}$. The targeted 72-h rectal temperature for WBC was $33-34{ }^{\circ} \mathrm{C}$, versus $34-35{ }^{\circ} \mathrm{C}$ for SHC. After the initial $72 \mathrm{~h}$ the rectal temperature was increased for both $\mathrm{TH}$ methods to $36.5^{\circ} \mathrm{C}$ via increasing the temperature $0.5^{\circ} \mathrm{C} \mathrm{h}^{-1}$. Patients that were not in the targeted temperature range for $>1 \mathrm{~h}$ were excluded.

Amplitude-integrated electroencephalography (aEEG) findings were defined as severely abnormal based on continuous low voltage, burst suppression, or flat tracing in the ground pattern, versus moderately abnormal based on discontinuous normal voltage [26-28]. Newborns diagnosed as HIE that did not meet all the criteria for TH constituted the mild HIE group. Newborns in the neonatal intensive care unit with transient tachypnea, an Apgar score $>7$ at 1 and $5 \mathrm{~min}$, blood gas $\mathrm{pH}>7.30$ within $1 \mathrm{~h}$ after birth, and didn't have clinical or culture positivity for sepsis constituted the control group.

From all the included newborns $2 \mathrm{~mL}$ of blood and $2 \mathrm{~mL}$ of urine were collected 6 and $72 \mathrm{~h}$ after birth. The blood samples were centrifuged, and then the separated serum was stored at $-80{ }^{\circ} \mathrm{C}$ until analyzed for interleukin (IL)-6, IL-1 $\beta$, tumor necrosis factor-alpha (TNF- $\alpha$ ), brainspecific creatine kinase (CK-BB), protein S100B via enzyme-linked immunosorbent assay, and neuron-specific enolase (NSE) and protein S100 via enzyme immunoradiometric assay. Urine lactate and creatinine levels were measured in fresh urine samples. Lactate was measured via the colorimetric lactate oxidase method and creatinine 
was measured via the enzymatic creatinine method, using a Cobas Integra 800 analyzer (Roche Diagnostics).

The newborns were evaluated at age 12 months for disability, neuromotor retardation, and mortality. Cognitive, language, and motor development at 12 months were evaluated using the Bayley Scales for Infant and Toddler Development-III (BSID- III) [29]. Those with a cognitive, language, or motor combined score 2 standard deviations lower than the mean BSID-III score, total loss of vision, or cerebral palsy were considered severely disabled. Those with a cognitive, language, or motor combined score 1 standard deviation lower than the BSID-III mean were defined as neuromotor retardation. Those with normal neurological examination findings without audio or visual problems, and those with a cognitive, language, and motor combined BSID-III score $>85$ were considered disability free.

\section{Statistical analysis}

Statistical analysis was performed using PASW v.18.0 (Predictive Analytics Software, a registered trademark of SPSS, Inc.) and Statistica v.8.0 (demo version). The distribution of continuous variables was evaluated using the ShapiroWilks test. Continuous variables with normal distribution were compared between groups using one-way ANOVA and the Scheffe post hoc test for multiple comparisons was used to determine difference between groups. Continuous variables not normally distributed were compared between groups using the Kruskal-Wallis test and Dunn test. Findings at the 12-month evaluation were compared between groups using the Mann-Whitney $U$ test. The Wilcoxon signed-rank test was used to compare findings at 6 and $72 \mathrm{~h}$ within groups. The Fisher-Freeman exact test was used when the expected value rule wasn't fulfilled, and the chi-square was used to evaluate the relationships between the categorical variables. Continuous variables are shown as mean \pm SD or median (IQR), depending on the distribution. The level of statistical significance was set at $P<0.05$.

\section{Results}

During the study period, 54 newborns were diagnosed as HIE, of which 11 were excluded because they were aged $>6 \mathrm{~h}$ at the time of randomization, 4 were excluded because died before $6 \mathrm{~h}$, and 1 was excluded due to a congenital malformation. Ten newborns not meeting criteria for $\mathrm{TH}$ were included in the mild HIE group. Of 28 infants meeting criteria for $\mathrm{TH}, 15$ were randomly allocated into group receiving $\mathrm{SHC}$ and 13 were allocated into group receiving WBC. One of the newborns in the WBC group was later excluded from the study because of the development of treatmentresistant hypotension that resulted in discontinue of the cooling therapy. In addition, serum and urine samples were not timely collected in 1 patient in the SHC group, 2 patients in the WBC group, 3 patients in the mild HIE group, and 1 case in the control group. After that the SHC group included 14 patients, the WBC group included 10 patients, the mild HIE group included 7 patients and the control group included 9 patients. The targeted rectal temperature was maintained for $72 \mathrm{~h}$ in all the patients in the SHC and WBC groups. Baseline patient characteristics in the SHC and WBC groups were similar $(p>0.05)$. Baseline patient characteristics in all groups are shown in Table 2, and biomarker levels at 6 and $72 \mathrm{~h}$ are given in Tables 3 and 4. The IL- 6 level at $6 \mathrm{~h}$ was similar in the SHC and WBC groups $(P>0.05)$, and was significantly higher than in the control group $(P=0.026$ for SHCcontrol and $P=0.015$ for WBC- control). The serum protein S100 level at $6 \mathrm{~h}$ was similar in the SHC and WBC groups $(P>0.05)$, and was significantly higher than in the control group $(P=0.013$ for SHC- control and $P=0.031$ for WBC- control). The $\mathrm{L} / \mathrm{C}$ ratio at $6 \mathrm{~h}$ was similar in the SHC and WBC groups $(P>0.05)$, and was significantly higher than in the mild HIE group ( $P=0.008$ for SHC- mild HIE and $P=0.014$ for WBC- mild HIE) and control group $(P=0.001$ for SHC- control and $P=0.002 \mathrm{WBC}$ - control). The levels of all the other biomarkers (serum IL-1 $\beta$, TNF- $\alpha$, NSE, $\mathrm{CKBB}$, and urine S100B) at $6 \mathrm{~h}$ were similar in each group $(P>0.05)$. The IL-6 level at $72 \mathrm{~h}$ was similar in the SHC and WBC groups $(P>0.05)$, and was significantly higher than in the mild HIE group $(P=0.004$ for SHC- mild HIE and $P=0.003$ for WBC- mild HIE) and control group $(P=0.018$ for SHC- control and $P=$ 0.014 for WBC- control). The levels of all other biomarkers at $72 \mathrm{~h}$ were similar in each group $(P>0.05)$.

The IL-6 level decreased significantly from 6 to $72 \mathrm{~h}$ only in the mild HIE group $(P=0.028)$. The CK-BB level decreased significantly from 6 to $72 \mathrm{~h}$ in all groups $(P<0.05)$ and the $\mathrm{L} / \mathrm{C}$ ratio decreased significantly from 6 to $72 \mathrm{~h}$ in the SHC $(P=0.008), \mathrm{WBC}(P=0.018)$, and control $(P=0.028)$ groups. The other biomarker levels did not change significantly between 6 and $72 \mathrm{~h}$ in any of the groups. Additionally, the difference between 6 and $72 \mathrm{~h}$ for all the biomarkers was calculated in the SHC and WBC groups in order to determine if the effect of the 2 methods differed; the increase or decrease in each biomarker between 6 and $72 \mathrm{~h}$ was determined in percentages and there weren't any significant differences between the 2 groups $(P>0.05)$.

At the age 12 months evaluation in the SHC group $(n=14) 5$ of the patients had died, 5 were severely disabled, 1 had neuromotor retardation, and 3 were disability free, whereas in the WBC group $(n=10) 5$ of the patients had died, 2 were severely disabled, and 3 were disability free. At the age 12 months evaluation all 7 of the patients in the mild HIE group were alive and 
Table 2 Baseline patient characteristics

\begin{tabular}{|c|c|c|c|c|c|}
\hline & SHC $(n=14)$ & WBC $(n=10)$ & Mild HIE $(n=7)$ & Control $(n=9)$ & $P$ \\
\hline Gestational age (weeks) & $38.6 \pm 1.1$ & $38.9 \pm 1.0$ & $38.8 \pm 1.1$ & $38.8 \pm 0.8$ & 0.931 \\
\hline Birth weight (g) & $3183 \pm 501$ & $3218 \pm 445$ & $3410 \pm 306$ & $3081 \pm 289$ & 0.480 \\
\hline Head circumference $(\mathrm{cm})$ & $34.7 \pm 1.1$ & $34.7 \pm 0.7$ & $34.5 \pm 1.0$ & $34.6 \pm 0.6$ & 0.945 \\
\hline Male & $4(28.6)$ & $3(30.0)$ & $2(28.6)$ & $4(44.4)$ & 0.905 \\
\hline Delivery via cesarean section & $2(14.3)$ & $4(40.0)$ & $2(28.6)$ & $3(33.3)$ & 0.512 \\
\hline Birth in the treatment center & $1(7.1)^{a}$ & $0(0.0)^{a}$ & $0(0.0)^{a}$ & $7(77.8)^{b}$ & $<0.001$ \\
\hline Age at group randomization (h) & $5.4 \pm 1.6$ & $5.9 \pm 0.3$ & $5.3 \pm 1.1$ & $4.6 \pm 1.9$ & 0.225 \\
\hline Rectal temperature at group randomization $\left({ }^{\circ} \mathrm{C}\right)$ & $34.1 \pm 0.9$ & $34.4 \pm 1.3$ & NA & NA & 0.615 \\
\hline Existence of clinical convulsions & $13(92.9)^{a}$ & $9(90.0)^{a}$ & $0(0.0)^{b}$ & $0(0.0)^{b}$ & $<0.001$ \\
\hline Invasive mechanical ventilation & $13(92.9)^{a}$ & $9(90.0)^{a}$ & $2(28.6)^{b}$ & $0(0.0)^{b}$ & $<0.001$ \\
\hline \multicolumn{6}{|l|}{ 5-min Apgar score $(n=35)$} \\
\hline $0-3$ & $5(50.0)$ & $4(40.0)$ & $0(0.0)$ & $0(0.0)$ & \\
\hline $4-6$ & $5(50.0)$ & $6(60.0)$ & $5(83.3)$ & $0(0.0)$ & \\
\hline $7-10$ & $0(0.0)$ & $0(0.0)$ & $1(16.7)$ & $9(100)$ & \\
\hline \multicolumn{6}{|l|}{ 10-min Apgar score $(n=24)$} \\
\hline $0-3$ & $1(14.3)$ & $3(75.0)$ & $0(0.0)$ & $0(0.0)$ & \\
\hline $4-6$ & $6(85.7)$ & $1(25.0)$ & $1(25.0)$ & $0(0.0)$ & \\
\hline $7-10$ & $0(0.0)$ & $0(0.0)$ & $3(75)$ & $9(100)$ & \\
\hline \multicolumn{6}{|l|}{ Blood gas analysis within $1 \mathrm{~h}$ post birth } \\
\hline $\mathrm{pH}$ & $6.9 \pm 0.2^{a}$ & $7.0 \pm 0.1^{a}$ & $7.0 \pm 0.1^{\mathrm{a}}$ & $7.30 \pm 0.1^{b}$ & 0.001 \\
\hline Base excess $\left(\mathrm{mmol} \mathrm{L}^{-1}\right)$ & $-17.7 \pm 2.9^{\mathrm{a}}$ & $-19.6 \pm 1.2^{a}$ & $-17.8 \pm 8.9^{\mathrm{a}}$ & $-2.6 \pm 1.3^{b}$ & $<0.001$ \\
\hline \multicolumn{6}{|l|}{ aEEG before randomization } \\
\hline Normal & $0(0.0)$ & $0(0.0)$ & $7(100)$ & NA & $<0.001$ \\
\hline Moderate abnormality & $3(21.4)$ & $1(10.0)$ & $0(0.0)$ & NA & \\
\hline Severe abnormality & $11(78.6)$ & $9(90.0)$ & $0(0.0)$ & NA & \\
\hline \multicolumn{6}{|l|}{ Sarnat stage } \\
\hline Stage I & $0(0.0)$ & $0(0.0)$ & $7(100)$ & NA & $<0.001$ \\
\hline Stage $\|$ & $3(21.4)$ & $1(10.0)$ & $0(0.0)$ & NA & \\
\hline Stage III & $11(78.6)$ & $9(90.0)$ & $0(0.0)$ & NA & \\
\hline
\end{tabular}

Values are given as median \pm SD, or number of patients and percentage

${ }^{a}$ and $^{\mathrm{b}}$ denote differences between groups, according to post hoc test. There is a significant difference data shown with different letters $(P<0.05)$

Table 3 Biomarker levels at $6 \mathrm{~h}$

\begin{tabular}{lcccr}
\hline Biomarkers & SHC group $(n=14)$ & WBC group $(n=10)$ & Mild HIE group $(n=7)$ & Control group $(n=9)$ \\
\hline IL-6 $\left(\mathrm{pg} \mathrm{mL}^{-1}\right)$ & $49.5^{\mathrm{a}}(15.8-219.9)$ & $46.7^{\mathrm{a}}(33.1-413.5)$ & $24.7^{\mathrm{a}, \mathrm{b}}(14.0-69.6)$ & $3.8^{\mathrm{b}}(2.8-6.6)$ \\
$\mathrm{IL}-1 \beta\left(\mathrm{pg} \mathrm{mL}{ }^{-1}\right)$ & $2.2(2.1-2.3)$ & $2.5(2.1-3.0)$ & $2.1(2.0-2.6)$ & $2.1(2.0-2.2)$ \\
TNF-a $\left(\mathrm{pg} \mathrm{mL}^{-1}\right)$ & $15.2(10.8-25.6)$ & $15.8(13.7-41.6)$ & $20.3(13.9-25.6)$ & $15.3(13.1-24.4)$ \\
NSE $\left(\mu \mathrm{g} \mathrm{L}^{-1}\right)$ & $0.58(0.44-1.62)$ & $0.67(0.48-2.65)$ & $0.49(0.37-2.13)$ & $0.45(0.36-0.51)$ \\
S100B $\left(\mathrm{ng} \mathrm{mL}^{-1}\right)$ & $0.08(0.07-0.09)$ & $0.12(0.07-0.15)$ & $0.11(0.08-0.15)$ & $0.07(0.06-0.08)$ \\
S100 $\left(\mathrm{ng} \mathrm{L}^{-1}\right)$ & $17.5^{\mathrm{a}}(5.6-60.4)$ & $15.3^{\mathrm{a}}(7.7-86.9)$ & $1.7^{\mathrm{a}, \mathrm{b}}(0.8-25.6)$ & $1.9^{\mathrm{b}}(0.7-4.7)$ \\
CKBB $\left(\mathrm{ng} \mathrm{mL} \mathrm{mL}^{-1}\right)$ & $1.9(1.5-3.0)$ & $2.1(1.4-3.9)$ & $1.9(1.4-2.3)$ & $1.4(1.1-1.8)$ \\
L/C ratio & $9.24^{\mathrm{a}}(1.32-43.89)$ & $3.00^{\mathrm{a}}(0.82-34.60)$ & $0.05^{\mathrm{b}}(0.03-0.11)$ & $0.04^{\mathrm{b}}(0.03-0.08)$ \\
\hline
\end{tabular}

Data shown as median (IQR)

${ }^{\mathrm{a}}$ and ${ }^{\mathrm{b}}$ denote differences between groups, according to post hoc test. There is a significant difference data shown with different letters $(P<0.05)$ 
Table 4 Biomarker levels at $72 \mathrm{~h}$

\begin{tabular}{lcccr}
\hline Biomarkers & SHC group $(n=14)$ & WBC group $(n=10)$ & Mild HIE group $(n=7)$ & Control group $(n=9)$ \\
\hline IL-6 $\left.(\mathrm{pg} \mathrm{mL})^{-1}\right)$ & $64.2^{\mathrm{a}}(30.4-118.0)$ & $43.0^{\mathrm{a}}(33.1-416.0)$ & $4.3^{\mathrm{b}}(1.2-17.6)$ & $3.0^{\mathrm{b}}(1.3-6.0)$ \\
$\mathrm{IL}-1 \beta\left(\mathrm{pg} \mathrm{mL}^{-1}\right)$ & $2.2(2.0-2.3)$ & $2.2(2.1-2.6)$ & $2.3(2.1-2.7)$ & $2.1(2.0-2.2)$ \\
TNF-a $\left(\mathrm{pg} \mathrm{mL}^{-1}\right)$ & $19.5(12.5-41.7)$ & $17.0(13.3-25.3)$ & $24.3(20.2-40.6)$ & $15.7(10.8-16.7)$ \\
NSE $\left(\mathrm{pg} \mathrm{L}^{-1}\right)$ & $0.51(0.38-0.74)$ & $0.57(0.38-1.70)$ & $1.01(0.40-1.93)$ & $0.38(0.32-0.47)$ \\
S100B $\left(\mathrm{ng} / \mathrm{ml}^{-1}\right.$ & $0.08(0.07-0.15)$ & $0.10(0.06-0.15)$ & $0.12(0.07-0.21)$ & $0.08(0.07-0.12)$ \\
S100 $\left(\mathrm{ng} \mathrm{L}^{-1}\right)$ & $2.9(0.5-15.5)$ & $9.5(0.3-29.8)$ & $1.6(0.8-3.6)$ & $1.5(0.4-3.8)$ \\
CKBB $\left(\mathrm{ng} \mathrm{mL}^{-1}\right)$ & $1.0(0.6-1.7)$ & $0.8(0.5-1.5)$ & $0.9(0.7-1.1)$ & $1.0(0.8-1.1)$ \\
L/C ratio & $0.08(0.04-0.27)$ & $0.06(0.04-0.16)$ & $0.05(0.03-0.06)$ & $0.03(0.02-0.04)$ \\
\hline
\end{tabular}

Data shown as median (IQR)

${ }^{\mathrm{a}}$ and ${ }^{\mathrm{b}}$ denote differences between groups, according to post hoc test. There is a significant difference data shown with different letters $(P<0.05)$

disability free. Among the 31 HIE patients in the study, at age 12 months 18 were adverse outcomes (died, severe disability, or neuromotor retardation) and 13 were favorable outcomes (living without disability). The serum IL-6 level and urine $\mathrm{L} / \mathrm{C}$ ratio at 6 and $72 \mathrm{~h}$ were significantly higher in the patients that had adverse outcomes than in the patients that had favorable outcomes at 12 months (IL-6: $P=0.049$ and $P=0.013$, respectively; $\mathrm{L} / \mathrm{C}$ ratio: $P<0.001$ and $P=0.027$, respectively). There weren't any significant relationships between the other 6th or 72nd hour biomarker levels and 12th month outcomes (Tables 5 and 6).

\section{Discussion}

In the present study there weren't any differences between the effects of SHC and WBC on the evaluated biomarkers in newborns with moderate and severe HIE. The IL- 6 level and $\mathrm{L} / \mathrm{C}$ ratio at 6 and $72 \mathrm{~h}$ in the patients that had died, had severe disability, and had neuromotor retardation at the time of the 12-month evaluation were significantly higher than in those that were alive without disability at month 12.

Although the precise mechanism of cellular damage caused by hypoxia-ischemia remains unknown, energy deficiency, excitatory neurotransmitters and free oxygen radicals are considered to contribute to the cascade of events leading to injury [30]. In addition, inflammation is known to play an important role in the pathogenesis of HIE [30]. Hypoxia-ischemia is followed by cerebral and peripheral immune response. Microglia and astrocytes become activated on one hand, while peripheral monocytes infiltrate the brain due to disrupted bloodbrain barrier on the other [8]. Activated inflammatory cells release pro-inflammatory cytokines and chemokines such as IL- 1 , IL-2, IL- 6 , IL- 8 , TNF- $\alpha$, and interferons $[8,30]$. As a result, inflammatory biomarkers' levels increase in HIE. On the other hand, various intracellular biomarkers like glial fibrillary acidic protein, NSE, and Protein S100 shift to extracellular compartment due to cell damage during HIE [31].

Researchers are trying to identify a biomarker suitable for diagnosing HIE, and for predicting the severity of disease and prognosis in the early period. Many biomarkers in blood, urine, and cerebrospinal fluid (CSF) have been studied, some of which were reported to be promising [21, 23]. The present study analyzed biomarkers that had been previously studied and were reported to be promising.

Nagdyman et al. [32] studied CK-BB, protein S100, and NSE levels in cord blood and serum collected at 2, 6, 12, and $24 \mathrm{~h}$ post birth in 7 newborns with moderate and severe HIE, and in 22 with mild HIE. The protein S100 and CK-BB levels in all the newborns with HIE at all time points were significantly higher than in the control group.

Table 5 The relationship between biomarker levels at $6 \mathrm{~h}$ and outcomes at age 12 months

\begin{tabular}{lcc}
\hline Biomarkers & Patients with adverse outcomes $(n=18)$ & Patients with favorable outcomes $(n=13)$ \\
\hline IL-6 $\left(\mathrm{pg} \mathrm{mL}^{-1}\right)$ & $121.1(31.4-334.3)^{*}$ & $33.2(13.0-61.7)$ \\
IL-1 $\beta\left(\mathrm{pg} \mathrm{mL}^{-1}\right)$ & $2.3(2.1-2.5)$ & $2.3(2.0-2.5)$ \\
TNF-a $\left(\mathrm{pg} \mathrm{mL}^{-1}\right)$ & $16.6(10.8-32.7)$ & $16.5(13.3-21.0)$ \\
NSE $\left(\mathrm{g} \mathrm{L}^{-1}\right)$ & $0.55(0.44-1.10)$ & $1.31(0.46-2.15)$ \\
S100B $\left(\mathrm{ng} \mathrm{mL}^{-1}\right)$ & $0.08(0.06-0.13)$ & $0.08(0.07-0.15)$ \\
S100 $\left(\mathrm{ng} \mathrm{L}^{-1}\right)$ & $13.5(5.8-31.0)$ & $22.4(1.3-136.4)$ \\
CKBB $\left(\mathrm{ng} \mathrm{mL}^{-1}\right)$ & $2.1(1.5-3.5)$ & $1.9(1.4-2.4)$ \\
L/C ratio & $19.0(2.64-47.89)^{*}$ & $0.12(0.04-0.36)$ \\
\hline
\end{tabular}

Data shown as median (IQR)

*There is a significant difference between groups $(P<0.05)$ 
Table 6 The relationship between biomarker levels at $72 \mathrm{~h}$ and outcomes at age 12 months

\begin{tabular}{lcc}
\hline Biomarkers & Patients with adverse outcomes $(n=18)$ & Patients with favorable outcomes $(n=13)$ \\
\hline $\mathrm{IL}-6\left(\mathrm{pg} \mathrm{mL}{ }^{-1}\right)$ & $60.3(29.1-121.1)^{*}$ & $24.6(3.9-45.0)$ \\
$\left.\mathrm{IL}-1 \beta(\mathrm{pg} \mathrm{mL})^{-1}\right)$ & $2.1(2.0-2.2)$ & $2.3(2.1-2.7)$ \\
TNF-a $\left(\mathrm{pg} \mathrm{mL}^{-1}\right)$ & $17.7(12.2-41.3)$ & $22.8(15.7-31.9)$ \\
NSE $\left(\mu \mathrm{g} \mathrm{L}^{-1}\right)$ & $0.52(0.38-0.74)$ & $0.98(0.44-2.13)$ \\
S100B $\left(\mathrm{ng} \mathrm{mL}^{-1}\right)$ & $0.09(0.06-0.12)$ & $0.11(0.07-0.21)$ \\
S100 $\left(\mathrm{ng} \mathrm{L}^{-1}\right)$ & $1.9(0.4-15.8)$ & $3.5(0.7-20.1)$ \\
CKBB $\left(\mathrm{ng} \mathrm{mL}^{-1}\right)$ & $0.8(0.6-1.5)$ & $1.0(0.7-1.3)$ \\
L/C ratio & $0.13(0.04-0.26)^{*}$ & $0.04(0.03-0.06)$ \\
\hline
\end{tabular}

Data shown as median (IQR)

*There is a significant difference between groups $(P<0.05)$

In addition, the serum protein S100 and CK-BB levels at 2 and $6 \mathrm{~h}$ were significantly higher in the newborns with moderate and severe HIE than in those with mild HIE. There wasn't a significant difference in the serum NSE level between the newborns with HIE and the control group at any time point. Similarly, in the present there wasn't a significant difference in the serum NSE level between the newborns with HIE and the control group. Additionally, the protein S100 level at $6 \mathrm{~h}$ was significantly higher in the newborns with moderate and severe HIE (SHC and WBC) than in the control group. Moreover, in contrast to Nagdyman et al.'s [30] study there wasn't a significant difference in the serum CK-BB level between the present study's newborns with and without HIE, which might be because TH was administered in the present study's newborns with moderate and severe HIE, but not in Nagdyman et al.'s patients.

Gazzolo et al. [33] studied the urine S100B level at 0, 24, 48, and $96 \mathrm{~h}$ in newborns with HIE and healthy controls. They reported that the urine S100B level in the newborns with HIE that died at age $1-7 \mathrm{~d}(n=12)$ was significantly higher than in those that were alive on $\mathrm{d} 7(n=48)$ and the control group $(n=72)$. In the present study the urine S100B level was similar in the SHC, WBC, mild HIE, and control groups, and a non-significant correlation was observed between the adverse outcomes at month 12 , and the S100B level at 6 and $72 \mathrm{~h}$. The difference in findings between the present study and Gazzolo et al.'s might be due to administration of TH in the present study. Moreover, an earlier study [34] reported that the S100B level was significantly lower in newborns with HIE treated with $\mathrm{TH}$ than in newborns with similar properties with HIE that weren't treated with $\mathrm{TH}$.

Huang et al. [35] studied the urine $\mathrm{L} / \mathrm{C}$ ratio at 6 and 48-72 $\mathrm{h}$ in 40 newborns with HIE and 58 healthy controls. They observed that the urine $\mathrm{L} / \mathrm{C}$ ratio was significantly higher in the newborns with HIE and the mean ratio of urinary $\mathrm{L} / \mathrm{C}$ was significantly higher in the infants who had adverse outcomes (death, severe cerebral palsy,
BSID II score that was more than 2 SD below the mean score for age, blindness, or deafness) at month 12 than the infants with favorable outcomes (normal neurologic development or slight abnormalities in muscle tone and reflexes). A similar study by Ghotbi et al. [36] reported that the $\mathrm{L} / \mathrm{C}$ ratio at 6 and $24 \mathrm{~h}$ was significantly higher in 50 newborns with HIE than in 50 healthy controls. In the present study $\mathrm{TH}$ was administered in newborns with moderate and severe HIE, in contrast to the other studies, and the $\mathrm{L} / \mathrm{C}$ ratio was observed to be significantly higher in the newborns with moderate and severe HIE than in those in the mild HIE and control groups. Furthermore, the $\mathrm{L} / \mathrm{C}$ ratio was higher at 6 and $72 \mathrm{~h}$ in the present study's patients that had died, had severe disability, and had neuromotor retardation at month 12 than in those that were living without disability, as reported by Huang et al. [35]. These findings suggest that the urine $\mathrm{L} / \mathrm{C}$ ratio might be useful for identifying newborns with moderate and severe HIE, and for predicting disability and mortality.

Massaro et al. [9] studied the serum NSE and S100B levels at $0,12,24$, and $72 \mathrm{~h}$ of hypothermia in newborns with HIE that received TH using WBC and their relationship to neurodevelopmental results. They reported that there was a significant relationship between serum NSE and S100B levels, and neurodevelopmental results at month 15 . In the present study there wasn't a significant relationship between adverse outcomes month 12 , and NSE or S100B levels at 6 and $72 \mathrm{~h}$. It is possible that these different results may be due to the heterogeneity of the etiologies that lead to HIE, timing of the insult and variability of the severity.

Chalak et al. [20] administered WBC in 20 newborns with moderate and severe HIE, but not in 7 with mild HIE. They analyzed various neuronal and inflammatory biomarkers in the blood samples obtained at 6-24, 48, 72 , and $78 \mathrm{~h}$. They reported that the IL-6 level at 6-24 h was significantly higher in the newborns with moderate and severe HIE than in those with mild HIE. Furthermore, they noted that there was a significant relationship 
between the IL- 6 and TNF- $\alpha$ levels at $6-24 \mathrm{~h}$, and abnormal neurological results at 15-18 months. In the present study the IL-6 level at $6 \mathrm{~h}$ was significantly higher in the SHC and WBC groups than in the control group, and the IL-6 level at $72 \mathrm{~h}$ was significantly higher in the SHC and WBC groups than in the mild HIE and control groups. As reported by Chalak et al. [20], the IL6 level at 6 and $72 \mathrm{~h}$ in the present study's patients that had died, had severe disability, and had neuromotor retardation at month 12 was significantly higher than in those that were living without disability. In contrast to Chalak et al. [20], in the present study there wasn't a correlation between the TNF- $\alpha$ level at 6 and $72 \mathrm{~h}$, and adverse outcomes at month 12 .

Roka et al. [8] performed a study to determine if $\mathrm{TH}$ causes a change in serum cytokine levels in newborns with HIE. They administered WBC in 10 newborns with moderate and severe HIE, but didn't administer WBC in 8 newborns with moderate and severe HIE. The newborns with HIE that did and did not receive WBC were compared in terms of serum cytokine levels at 6,12 , and $24 \mathrm{~h}$ after birth. They reported that the IL6 level at $6 \mathrm{~h}$ was significantly lower in the WBC group than in the non-WBC group. They suggested based on this result that TH rapidly suppresses cytokine production as a response to asphyxia and that this might be an important mechanism associated with the neuroprotective effect of $\mathrm{TH}$. In the present study $\mathrm{SHC}$ or WBC was administered to each newborn with moderate and severe HIE, as withholding such treatment would have been unethical. Following TH, there weren't any significant differences regarding change in the biomarker levels between the 2 methods. The IL- 6 level at $6 \mathrm{~h}$ was significantly higher in the newborns with HIE (SHC, WBC, and mild HIE groups) than in the control group, which supports the notion that cytokines increase secondary to asphyxia. Moreover, there wasn't a significant change in the IL-6 level from 6 to $72 \mathrm{~h}$ in the SHC or WBC groups, whereas the IL-6 level at $72 \mathrm{~h}$ was significantly lower than at $6 \mathrm{~h}$ in the mild HIE group even though TH wasn't administered. This finding suggests that even if TH suppresses cytokine production, it can't decrease the cytokine level to normal within $72 \mathrm{~h}$ of birth in newborns with moderate or severe HIE.

The most important limitation of the present study is the small study population; however, to the best of our knowledge this prospective, randomized single-center study is the first to compare the effects of SHC and WBC on biomarker levels in newborns with HIE. Another limitation is that biomarkers in CSF weren't analyzed; had they been the findings might have differed. The biomarker levels were measured only in serum and urine samples, as they are more useful and their collection in less invasive.

\section{Conclusion}

There weren't any differences in the effects of SHC and WBC on the biomarkers evaluated in the present study. Serum IL-6 and protein S100 levels may be useful for diagnosing HIE, and the urine $\mathrm{L} / \mathrm{C}$ ratio may be useful for differentiating newborns with moderate and severe HIE from those with mild HIE. The serum IL-6 level and the $\mathrm{L} / \mathrm{C}$ ratio might also be useful for identifying cases of HIE that might result in disability or mortality. Additional larger scale and longer term studies might yield more generalizable findings.

\section{Abbreviations}

aEEG: Amplitude integrated electroencephalography; CKBB: Brain-specific creatine kinase; CSF: Cerebrospinal fluid; HIE: Hypoxic ischemic

encephalopathy; IL: Interleukin; L/C: Lactate/creatinine; NSE: Neuron spesific enolase; SHC: Selective head cooling; TH: Therapeutic hypothermia;

TNF: Tumor necrosis factor; WBC: Whole body cooling.

\section{Competing interests}

All authors declare no potential competing interests related to this paper.

\section{Authors' contributions}

Guarantor of integrity of the entire study: YÇ, AA. Study concepts: YÇ, AA. Study design: YÇ, AA. Definition of intellectual content: YÇ, AA. Literature research: YÇ. Clinical studies: YÇ, SG, KM, SA. Data acquisition: YÇ, SA, GE. Data analysis: YÇ, AA, GE. Statistical analysis: MAS. Manuscript preparation: YÇ, AA. Manuscript editing: YÇ, AA. Manuscript review: AA. All authors read and approved the final manuscript.

\section{Author details}

'Mersin University School of Medicine, Department of Neonatology Care Unit, 33343 Mersin, Turkey. ${ }^{2}$ Mersin University Faculty of Medicine, Department of Neonatology, 33343 Mersin, Turkey. ${ }^{3}$ Mersin University School of Medicine, Department of Neonatology, 33343 Mersin, Turkey. ${ }^{4}$ Mersin University Faculty of Medicine, Department of Pediatric Neurology, 33343 Mersin, Turkey. ${ }^{5}$ Mersin University Faculty of Medicine, Department of Biochemistry, 33343 Mersin, Turkey. ${ }^{6}$ Mersin University Faculty of Medicine, Department of Biostatistics, 33343 Mersin, Turkey.

Received: 13 May 2015 Accepted: 7 October 2015

Published online: 15 October 2015

\section{References}

1. Jacobs SE, Berg M, Hunt R, Tarnow-Mordi WO, Inder TE, Davis PG. Cooling for newborns with hypoxic ischaemic encephalopathy. Cochrane Database Syst Rev. 2013. doi:10.1002/14651858.

2. Takenouchi T, Iwata O, Nabetani M, Tamura M. Therapeutic hypothermia for neonatal encephalopathy. Brain Dev. 2012;34:165-70.

3. Edwards AD, Brocklehurst P, Gunn AJ, Halliday H, Juszczak E, Levene M, et al. Neurological outcomes at 18 months of age after moderate hypothermia for perinatal hypoxic ischaemic encephalopathy: synthesis and meta-analysis of trial data. BMJ. 2010;340:C363.

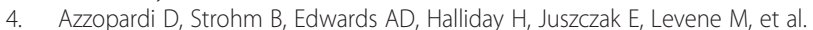
Steering Group and TOBY Cooling Register participants. Treatment of asphyxiated newborns with moderate hypothermia in routine clinical practice: how cooling is managed in the UK outside a clinical trial. Arch Dis Child Fetal Neonatal Ed. 2009;94:260-4.

5. Hagmann CF, Brotschi B, Bernet V, Latal B, Berger TM, Robertson NJ. Hypothermia for perinatal asphyxial encephalopathy. Swiss Med Wkly. 2011. doi:10.4414/smw.2011.13145.

6. Kracer B, Hintz SR, Van Meurs KP, Lee HC. Hypothermia therapy for neonatal hypoxic Ischemic encephalopathy in the State of California. J Pediatr. 2014. doi:10.1016/j.jpeds.2014.04.052.

7. Gardiner J, Wagh D, McMichael J, Hakeem M, Rao S. Outcomes of hypoxic ischaemic encephalopathy treated with therapeutic hypothermia using cool gel packs experience from Western Australia. Eur J Paediatr Neurol. 2014;18:391-8. 
8. Róka A, Bekő G, Halász J, Toldi G, Lakatos P, Azzopardi D, et al. Changes in serum cytokine and cortisol levels in normothermic and hypothermic term neonates after perinatal asphyxia. Inflamm Res. 2013;62:81-7.

9. Massaro AN, Chang T, Baumgart S, McCarter R, Nelson KB, Glass P. Biomarkers S100B and neuron-specific enolase predict outcome in hypothermia-treated encephalopathic newborns. Pediatr Crit Care Med. 2014;15:615-22.

10. Austin T, Shanmugalingam S, Clarke P. To cool or not to cool? Hypothermia treatment outside trial criteria. Arch Dis Child Fetal Neonatal Ed. 2013;98:451-3.

11. Daetwyler K, Brotschi B, Berger TM, Wagner BP. Feasibility and safety of passive cooling in a cohort of asphyxiated newborn infants. Swiss Med Wkly. 2013. doi:10.4414/smw.2013.13767.

12. Olsen SL, Dejonge M, Kline A, Lipsten E, Song D, Anderson B, et al. Optimizing therapeutic hypothermia for neonatal encephalopathy. Pediatrics. 2013;131:591-603.

13. Kasdorf E, Perlman JM. Strategies to prevent reperfusion injury to the brain following intrapartum hypoxia-ischemia. Semin Fetal Neonatal Med. 2013;18:379-84.

14. Allen KA. Moderate hypothermia: is selective head cooling or whole body cooling better? Adv Neonatal Care. 2014;14:113-8.

15. Peliowski-Davidovich A, Canadian Paediatric Society, Fetus and Newborn Committee. Hypothermia for newborns with hypoxic ischemic encephalopathy. Paediatr Child Health. 2012;17:41-6.

16. Azzopardi DV, Strohm B, Edwards AD, Dyet L, Halliday HL, Juszczak E, et al. TOBY Study Group. Moderate hypothermia to treat perinatal asphyxial encephalopathy. N Engl J Med. 2009;361:1349-58.

17. Gunn AJ, Gluckman PD. Head cooling for neonatal encephalopathy: the state of the art. Clin Obstet Gynecol. 2007;50:636-51.

18. Shankaran S, Laptook AR, Ehrenkranz RA, Tyson JE, McDonald SA, Donovan $E F$, et al. Whole-body hypothermia for neonates with hypoxic-ischemic encephalopathy. N Engl J Med. 2005;353:1574-84.

19. Gluckman PD, Wyatt JS, Azzopardi D, Ballard R, Edwards AD, Ferriero DM, et al. Selective head cooling with mild systemic hypothermia after neonatal encephalopathy: multicentre randomised trial. Lancet. 2005;365:663-70.

20. Chalak LF, Sánchez PJ, Adams-Huet B, Laptook AR, Heyne RJ, Rosenfeld CR. Biomarkers for severity of neonatal hypoxic-ischemic encephalopathy and outcomes in newborns receiving hypothermia therapy. J Pediatr. 2014;164:468-74.

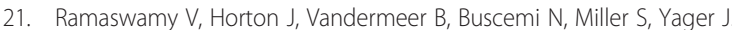
Systematic review of biomarkers of brain injury in term neonatal encephalopathy. Pediatr Neurol. 2009;40:215-26.

22. Ferriero DM, Bonifacio SL. The search continues for the elusive biomarkers of neonatal brain injury. J Pediatr. 2014;164:438-40.

23. Douglas-Escobar M, Weiss MD. Biomarkers of hypoxic-ischemic encephalopathy in newborns. Front Neurol. 2012;3:144.

24. American College of Obstetricians and Gynecologists (ACOG). Neonatal encephalopathy and cerebral palsy: executive summary. Obstet Gynecol. 2004;103:780-1.

25. Levene MI, de Vries L. Hypoxic-ischemic ensephalopathy. In: Martin RJ, Fanaroff AA, Walsh MC, editors. Neonatal-perinatal medicine. Philadelphia: Elsevier; 2006. p. 938-56.

26. Horn AR, Swingler GH, Myer L, Linley LL, Raban MS, Joolay Y, et al. Early clinical signs in neonates with hypoxic ischemic encephalopathy predict an abnormal amplitude-integrated electroencephalogram at age 6 hours. BMC Pediatr. 2013. doi:10.1186/1471-2431-13-52.

27. Hellstrom-Westas L, de Vries LS, Rosen I. Atlas of amplitude-integrated EEGs in the newborn. 2nd ed. London: Informa Healthcare; 2008.

28. Thoresen M, Hellström-Westas L, Liu X, de Vries LS. Effect of hypothermia on amplitude-integrated electroencephalogram in infants with asphyxia. Pediatrics. 2010;126:131-9.

29. Bayley N. The bayley scales of infant and toddler development. 3rd ed. San Antonio: The Psychological Corporation; 2006.

30. Guo MF, Yu JZ, Ma CG. Mechanisms related to neuron injury and death in cerebral hypoxic ischaemia. Folia Neuropathol. 2011;49:78-87.

31. Mir IN, Chalak LF. Serum biomarkers to evaluate the integrity of the neurovascular unit. Early Hum Dev. 2014;90:707-11

32. Nagdyman N, Kömen W, Ko HK, Müller C, Obladen M. Early biochemical indicators of hypoxic-ischemic encephalopathy after birth asphyxia. Pediatr Res. 2001:49:502-6.
33. Gazzolo D, Frigiola A, Bashir M, Iskander I, Mufeed $H$, Aboulgar $H$, et al. Diagnostic accuracy of S100B urinary testing at birth in full-term asphyxiated newborns to predict neonatal death. PLoS One. 2009. doi:10.1371/journal.pone.0004298.

34. Roka A, Kelen D, Halasz J, Beko G, Azzopardi D, Szabo M. Serum S100B and neuron-specific enolase levels in normothermic and hypothermic infants after perinatal asphyxia. Acta Paediatr. 2012;101:319-23.

35. Huang CC, Wang ST, Chang YC, Lin KP, Wu PL. Measurement of the urinary lactate:creatinine ratio for the early identification of newborn infants at risk for hypoxic-ischemic encephalopathy. N Engl J Med. 1999;341:328-35.

36. Ghotbi N, Najibi B. Measurement of the urinary lactate/creatinine ratio for early diagnosis of the hypoxic-ischemic encephalopathy in newborns. Iran J Pediatr. 2010:20:35-40.

\section{Submit your next manuscript to BioMed Central and take full advantage of:}

- Convenient online submission

- Thorough peer review

- No space constraints or color figure charges

- Immediate publication on acceptance

- Inclusion in PubMed, CAS, Scopus and Google Scholar

- Research which is freely available for redistribution

Submit your manuscript at www.biomedcentral.com/submit
C) BioMed Central 